\title{
Mortality among very low birth weight infants after hospital discharge in a low resource setting
}

\author{
Yaser Abdallah ${ }^{1 *}$, Flavia Namiiro², Jolly Nankunda², Jamiru Mugalu² and Yvonne Vaucher ${ }^{3}$
}

\begin{abstract}
Background: Early discharge of very low birth weight infant (VLBW) in low resource settings is inevitable but to minimize mortality of these infants after discharge we need to identify the death attributes.

Method: A prospective cohort was conducted among 190 VLBW infants discharged from Mulago Special Care Baby Unit (SCBU) with discharge weight of $<1500 \mathrm{~g}$ over an 8 months period. These infants were followed up with the aims of determining the proportion dead 3 months after discharge, identifying factors associated and possible causes of death.

Relevant data were captured, transferred in to STATA and imported to SPSS 12.0.1 for analysis. To determine factors associated with mortality bi-variable and multivariable regressions were conducted. A $p$-value of $<0.05$ was considered significant and 95\% confidence interval was used.

Results: Of the enrolled infants 164 (86.3\%) completed follow up. The median gestational age of study participants was 32 weeks (range 26-35 weeks), the mean discharge weight was $1119 \mathrm{~g}$ (range 760-1470 g), and 59.8\% were small for gestational age (SGA). During follow up 32 (19.5\%) infants died. Infants discharged with weight of $<1200 \mathrm{~g}$ accounted for $81.2 \%$ of the deaths. Majority of the deaths (68.7\%) occurred in the first month after discharge. Factors independently associated with mortality were discharge weight $<1000 \mathrm{~g}$ (OR 3.10, p 0.015) and not being SGA (OR 3.54, p 0.019). The main causes of death were presumed sepsis 50.0\% and suspected cot death (25.0\%).

Conclusion: Mortality after hospital discharge among VLBW infants is high. Discharge at weight $<1200 \mathrm{~g}$ may not be a safe practice. Measures to prevent sepsis and suspected cot death should be addressed prior to considering early discharge of these infants.
\end{abstract}

Keywords: Preterm neonates, Very low birth weight, Mortality

\section{Background}

It is estimated that more than 22 million babies born worldwide annually are of low birth weight $(<2500 \mathrm{~g})$ of whom $95.6 \%$ are in the low resource countries and this trend has not changed in the last 10 years $[1,2]$. Low birth weight babies account for $60-80 \%$ of all neonatal deaths $[3,4]$. Preterm VLBW babies' are at higher odds of mortality even beyond the neonatal period $[4,5]$. The prevalence of preterm/low birth weight babies in Uganda is estimated at $10-20 \%$ [6]. In Mulago Special Care Baby Unit (SCBU)

\footnotetext{
* Correspondence: yasam786@hotmail.com

${ }^{1}$ Department of Paediatrics and Child Health, Makerere University College of Health Sciences, P.O Box 7072, Kampala, Uganda

Full list of author information is available at the end of the article
}

(National referral hospital of Uganda), VLBW and extremely low birth weight babies account for $13.8 \%$ of admission and approximately $50 \%$ of these babies die prior to discharge [7].

Very low birth weight babies are usually hospitalized for longer periods for various reasons including respiratory distress, sepsis, feeding intolerance among others $[8,9]$. These babies present a challenge to their parents as well as the health care system [9]. Although Kangaroo Mother Care (KMC) has enabled early discharge of low birth weight babies [10], the higher odds of mortality among such babies stretching beyond the neonatal period has made the timing of their hospital discharge a subject of continued debate.

(c) The Author(s). 2018 Open Access This article is distributed under the terms of the Creative Commons Attribution 4.0 International License (http://creativecommons.org/licenses/by/4.0/), which permits unrestricted use, distribution, and 
The World Health Organization (WHO) has developed a more objective and flexible discharge criteria for low birth weight babies [11] but these have been difficult to adhere to especially in the developing countries due to limitation in resources. Many resource limited countries lack KMC facilities; in Uganda only 1/10 of health facilities do have facilities for KMC [12] and hence VLBW babies tend to be discharged at much smaller weights. Varying rates of survival of VLBW babies discharged early to continue home KMC have been described [13-16]; the outcome of such babies discharged from Mulago SCBU is not known.

The practice in SCBU is to discharge babies irrespective of their weight but once stable (i.e. off oxygen and antibiotics), gaining weight, having stable body temperature while in Kangaroo care, and tolerating $80 \mathrm{ml} / \mathrm{kg} /$ day of feeds (by cup/tube). These babies are followed up on a weekly basis till they attain a weight of $2500 \mathrm{~g}$. Whereas this method of discharge enables reduction in health care system constraint its safety needs to be elaborated. This study was aimed at throwing more light on proportion of VLBW infants discharged from Mulago SCBU with discharge weight of $<1500 \mathrm{~g}$ that die, factors associated and possible causes of death.

\section{Methods}

\section{Setting}

This study was conducted at the Mulago Hospital SCBU. Mulago hospital is a National Referral Hospital for Uganda and teaching hospital for Makerere University. Mulago Hospital SCBU is a level II neonatal unit. The unit admits on average 4600 babies annually with approximately $20 \%$ being VLBW babies.

The Mulago SCBU has a preterm, term and Kangaroo mother care sections (KMC). The preterm section has 19 incubators and 2 radiant warmers with minimal space between these equipment's. The KMC section can handle only 4 mother/infant pair at any one time. Due to the large admission volumes sharing of incubators/radiant warmers by babies is the norm.

With respect to staffing, the unit is served by 3 paediatricians, 16 nurses (working in 3 shifts per day), 2 intern and 2-4 Paediatrics resident doctors on rotational basis.

The most VLBW babies are offered during their stay in the unit include intravenous antibiotics and fluids mainly as boluses, phototherapy and nasal gastric tube feeds when needed. Maximum respiratory support available is with fixed expiratory valve Continuous Positive Airway Pressure (CPAP). Vital signs monitoring is done intermittently. Mothers/caregivers are responsible for feeding their babies on a two hourly basis.

Preterm neonates are discharged from the unit once they are off oxygen, tolerating $80 \mathrm{mls} / \mathrm{kg} /$ day of feeds and have started gaining weight. Due to lack of adequate space in the unit most of the time infants are discharged before regaining birth weight. Preterm neonates discharged are followed up in the preterm clinic which runs twice weekly at the SCBU.

These preterm infants are followed up on weekly basis in the preterm clinic where growth is monitored, supplements (multivitamin and iron) are refilled, feeds are readjusted (maximum feeding volume is $220 \mathrm{ml} / \mathrm{kg} /$ day), nasogastric tubes are replaced and unwell infants are readmitted and managed.

\section{Study population}

All infants discharged from Mulago SCBU whose birth weight was $\leq 1500 \mathrm{~g}$ and discharge weight $<1500 \mathrm{~g}$ if the parent consented and they had 2 reliable phone contacts.

\section{Sample size}

Sample size was estimated using Open Epi for frequency in population and assuming expected mortality among infants within 3 months of discharge (25.7\%) [14].

Sample Size (n) for 95\% Confidence Level was 173. Assuming a $10 \%$ loss to follow up the final sample size was $(n)=173+173 * 10 \%=190$.

\section{Procedure}

All infants of birth weight $\leq 1500 \mathrm{~g}$ admitted to Mulago Hospital SCBU between June 2013 and January 2014 were identified by the research assistant within $24 \mathrm{~h}$ of birth and gestational age ascertained using the New Ballard Score [17]. For infants who met inclusion criteria and where ready for discharge, the research assistant discussed with parents in detail and obtained written consent. Recruitment was conducted daily till the desired sample size was reached.

Recruited infants were given a study number for identification. A log book was put in place to ease tracking follow up dates for study participants. Phone contacts were exchanged and checked if they were working. Phone contact for principal investigator and research assistant were given to parents to call in case of any concern and parent's contacts were taken to easy follow up in case infant is not returned to clinic visits for follow up.

Data was captured at discharge and on the weekly follow up clinic by a trained research assistant. Parents who did not return the infants to the follow up clinic were called on phone and advised to return in the next visit. Parents who missed two consecutive visits and those not contactable were considered as lost to follow up.

In the case of parents who did not return to the follow up clinic because the infant had died, details related to death were obtained by research assistant from the parents.

\section{Data management and analysis}

Information captured in the data sheet was checked by the principle investigator for completeness and accuracy. The data sheets were stored in a locker. 
Data from the data sheets were entered into the computer using Microsoft Excel program. It was subsequently exported into STATA software package for analysis. Baseline characteristic of study participants were summarized in a table. The survival was computed as a ratio of study participants alive at 3 months after hospital discharge to the total number of study participants who completed study. Univariate analysis was conducted for continuous variables.

$P$ values of $<0.05$ were considered significant and confidence interval of $95 \%$ was used. Results were summarized in tables.

\section{Results}

Over an 8 month period (June 2013 to January 2014) 412 VLBW infants were admitted to the Special Care Baby Unit of whom 164 (39.8\%) died. Of those who survived to discharge 190 were recruited; 164 (86\%) infants completed study. Infants excluded from the study included 25 with incomplete data, 12 whose parents declined to consent and 21 whose parents had no reliable phone contacts.

Of the infants who were, enrolled and completed the study, the median gestational age was 32 weeks and the mean discharge weight was $1119 \mathrm{~g}$ (range 760-1470 g).

Twenty six (26) infants were loss to follow up (Table 1), twelve never returned for review and parents could not be reached on contacts they had left behind. Fourteen returned but by 3 months after discharge 4 had relocated, while 10 could not be reached.

There was high loss to follow up among mothers < 20 years of age $(11 / 34 \mathrm{p} 0.001)$ (Table 1$)$ which might be attributed to poor social support and also among mothers who had better income $(6 / 9 p 0.0002)$ which might be attributed to seeking health care somewhere else.

The average duration of hospital stay among study participants was 12.2 days (range 4-42 days). All infants were discharged on multivitamin drops, iron supplementation and oral aminophylline.

A majority of study infants were discharged on breast feeding with topping off through nasogastric tube, 11 were fully breast feeding and 23 fully tube feeding.

Two study infants were on formula feeds, both died, one from anemia and the other from presumed sepsis. Two of the enrolled infants had anomalies; one had a cleft lip and palate and the other had a patent ductus ateriosus with pulmonary stenosis; both died on follow up.

During follow up 32 infants died (Table 2). Likely cause of death was established by asking the mother to explain circumstances at the time of death.

Sixteen of study participants died from presumed sepsis based on mother's description of signs suggesting baby was unwell. Ten of these infants were re-hospitalized but died in hospital, 2 died on the way to hospital and 4 had
Table 1 Baseline characteristics of study participants

\begin{tabular}{|c|c|c|c|}
\hline Characteristics & $\begin{array}{l}\text { Completed follow up } \\
N=164(\%)\end{array}$ & $\begin{array}{l}\text { Loss to follow up } \\
N=26(\%)\end{array}$ & $p$-value \\
\hline \multicolumn{4}{|l|}{$\overline{S e x}$} \\
\hline Male & $71(43.3)$ & $12(46.1)$ & \\
\hline Female & $93(56.7)$ & $14(53.9)$ & \\
\hline \multicolumn{4}{|l|}{ Mode of delivery } \\
\hline SVD & $129(78.7)$ & $19(73.1)$ & 0.52 \\
\hline Caesarian section & $35(21.3)$ & $7(26.9)$ & \\
\hline \multicolumn{4}{|l|}{ Birth Weight } \\
\hline$<1000 \mathrm{~g}$ & $12(7.3)$ & $1(3.8)$ & 0.52 \\
\hline $1000-1200 \mathrm{~g}$ & $74(45.1)$ & $10(38.5)$ & 0.52 \\
\hline$>1200 \mathrm{~g}$ & 78 (47.6) & $15(57.7)$ & \\
\hline \multicolumn{4}{|l|}{ HIV exposure } \\
\hline Yes & $30(18.3)$ & $4(15.4)$ & 0.72 \\
\hline No & $134(81.7)$ & $22(84.6)$ & \\
\hline \multicolumn{4}{|c|}{ Small for Gestational Age (SGA) } \\
\hline Yes & $98(59.8)$ & $7(27.0)$ & \\
\hline No & $66(40.2)$ & $19(73.0)$ & \\
\hline \multicolumn{4}{|l|}{ Discharge Weight } \\
\hline$<1000 \mathrm{~g}$ & $39(23.8)$ & $6(23.0)$ & 0.94 \\
\hline $1000-1200 \mathrm{~g}$ & $77(47.0)$ & $11(42.3)$ & \\
\hline$>1200 \mathrm{~g}$ & $48(29.2)$ & $9(34.7)$ & \\
\hline \multicolumn{4}{|c|}{ Duration in continuous kangaroo } \\
\hline$<1$ week & $129(78.7)$ & $24(92.3)$ & 0.12 \\
\hline 1-2 weeks & $30(18.3)$ & $2(7.7)$ & \\
\hline$>2$ weeks & $5(3.0)$ & $0(0.0)$ & \\
\hline \multicolumn{4}{|l|}{ Maternal age } \\
\hline$<20$ years & $23(14.0)$ & $11(42.3)$ & 0.001 \\
\hline$\geq 20$ years & $141(86.0)$ & $15(57.7)$ & \\
\hline \multicolumn{4}{|l|}{ Maternal Parity } \\
\hline Primiparous & $52(31.7)$ & $9(34.6)$ & 0.76 \\
\hline $2-4$ & $89(54.3)$ & $16(61.5)$ & \\
\hline$>4$ & $23(14.0)$ & $1(3.9)$ & \\
\hline \multicolumn{4}{|l|}{ Maternal education } \\
\hline None & $7(4.3)$ & $1(3.8)$ & 0.92 \\
\hline Primary & 49 (29.9) & $13(50.0)$ & 0.046 \\
\hline Secondary & $81(49.4)$ & $9(34.6)$ & 0.16 \\
\hline Tertiary & $27(16.5)$ & $3(11.5)$ & 0.52 \\
\hline \multicolumn{4}{|c|}{ Maternal monthly income } \\
\hline Unemployed/Nil & $77(47.0)$ & $16(61.5)$ & \\
\hline $\begin{array}{l}<100,000 \\
\text { (Uganda shillings) }\end{array}$ & $84(51.2)$ & $4(15.4)$ & \\
\hline $\begin{array}{l}\geq 100,000 \\
\text { (Uganda shillings) }\end{array}$ & $3(1.8)$ & $6(23.1)$ & 0.0002 \\
\hline \multicolumn{4}{|l|}{ Parents living together } \\
\hline Yes & 138 (84.1) & $18(69.2)$ & \\
\hline
\end{tabular}


Table 1 Baseline characteristics of study participants (Continued)

\begin{tabular}{llll}
\hline Characteristics & $\begin{array}{l}\text { Completed follow up } \\
N=164(\%)\end{array}$ & $\begin{array}{l}\text { Loss to follow up } \\
N=26(\%)\end{array}$ & $p$-value \\
\hline No & $26(15.9)$ & $8(30.7)$ & 0.07 \\
KMC Supported & & & \\
yes & $34(79.3)$ & $4(15.4)$ & \\
No & $130(20.7)$ & $10(38.5)$ & 0.49 \\
Unknown & $0(0.0)$ & $12(46.1)$ & \\
Postmenstrual age at discharge & & 0.14 \\
CGA $<35$ weeks & $95(57.9)$ & $19(73.0)$ & \\
CGA $\geq 35$ weeks & $69(42.1)$ & $7(27.0)$ &
\end{tabular}

signs of being unwell but parents did not know what to do so infants died at home. Nine infants who died from presumed sepsis died within 1 month of discharge (Table 2).

With regards to eight infants who died from suspected cot death, the mothers described baby being completely well but found dead in the bed; all infants who died from suspected cot death had discharge weight $<1200 \mathrm{~g}$, with four of them at $<1000 \mathrm{~g}$. Four of these infants died at corrected gestational age of $<35$ weeks (Table 2). Eight infants who died from suspected cot death died within 1 month of discharge.

Cause of death of 4 infants could not be established. We were only able to ascertain that the infant had died but could not get details from the mother because we could not talk to her in person on phone for one reason or another. The infants who died from suspected aspiration included one who had cleft lip and palate, one extremely low birth weight $760 \mathrm{~g}$ whose feeding tube had

Table 2 Mortality and causes of mortality after hospital discharge

\begin{tabular}{|c|c|c|c|c|}
\hline $\begin{array}{l}\text { Discharge weight } \\
\text { (no) }\end{array}$ & $<1$ month & $1-2$ months & $>2$ months & Total (\%) \\
\hline \multicolumn{5}{|c|}{ Duration spent at home at time of death } \\
\hline$<1000 \mathrm{~g}(35)$ & 9 & 2 & 2 & $13(37.1 \%)$ \\
\hline $1000-1200 \mathrm{~g}(75)$ & 8 & 4 & 2 & $14(18.7 \%)$ \\
\hline$>1200 \mathrm{~g}(49)$ & 5 & - & - & $5(10.2 \%)$ \\
\hline TOTAL & 22 & 6 & 4 & 32 \\
\hline \multicolumn{5}{|l|}{ Causes of death } \\
\hline Presumed Sepsis & 9 & 4 & 3 & $50 \%$ \\
\hline No details & 3 & 1 & - & $12.5 \%$ \\
\hline $\begin{array}{l}\text { Suspected Cot } \\
\text { death }\end{array}$ & 8 & - & - & $25.0 \%$ \\
\hline $\begin{array}{l}\text { Congested } \\
\text { cardiac failure }\end{array}$ & 1 & - & - & $3.1 \%$ \\
\hline $\begin{array}{l}\text { Suspected } \\
\text { Aspiration }\end{array}$ & 1 & 1 & 1 & $9.4 \%$ \\
\hline
\end{tabular}

come out and one who was receiving breast feeding with top up of 40mls 2 hourly.

Discharge weight of $<1000 \mathrm{~g}$, postmenstrual age $<$ 35 weeks and not being small for gestational age were associated with mortality p 0.008, p 0.012 and p 0.001respectively (Table 3) but in the multivariate analysis (Table 4) discharge at postmenstrual age $<35$ weeks was not significant.

Although there was a trend towards parents living together improving chances of survival (139/163) it was not statistically significant (Table 3 ). None of the other social demographic characteristics was found to be associated with outcome.

\section{Discussion}

From this study we observed a mortality rate of $19.5 \%$ among VLBW infants discharged. This mortality rate is comparable to that observed in the other neighboring countries $[14,18,19]$ despite the fact that $70 \%$ of the infants we discharged weighed $<1200 \mathrm{~g}$. This can be explained by the fact that a majority $59.8 \%$ of our infants were small for gestational age.

Our mortality rate was relatively high compared to that seen in the developed countries and countries that use a higher discharge weight criteria $[13,15,16]$. Studies from settings that discharged infants at much higher body weight had far lower mortality rate since those infants would be more mature with better survival mechanisms including stable body temperature while in a cot, capable to feed orally and low risk for apnoea.

The mortality among our discharge infants was inversely related to discharge weight $<1000 \mathrm{~g}(13 / 37)$, 1000-1199 (13/73) and $>1200(6 / 54)$ this can be explained by the fact that the smaller the infant the more vulnerable they were to hypothermia, apnoea and sepsis. This observation is similar to that found in other studies that looked at discharge weight [18]. Discharging at weight $<1200 \mathrm{~g}$ in low resource setting may not be a safe practice.

Infants discharged at a postmenstrual age of $<35$ weeks had a higher odds of dying 25/95 (OR 3.16, p 0.012) compared to those discharged at $\geq 35$ weeks $(7 / 69)$. Most studies that looked at survival after discharge in low resource settings did not look at postmenstrual age. At 35 weeks of gestation most infants have a good suck and swallowing reflex [20] and the risk of apnoea is very small [21] this explains why mortality was relatively lower among infants discharged at a postmenstrual age $\geq 35$ weeks.

None of the social demographic characteristics was significantly associated with mortality in our study. This is contrary to findings from other studies that found maternal education, age, and race to be associated with outcome $[16,19]$. Whereas it may be perceived that education level should improve survival, in our setting no special 
Table 3 Association between baseline characteristics and outcome

\begin{tabular}{|c|c|c|c|c|}
\hline Characteristics & $\begin{array}{l}\text { Total } \\
164(\%)\end{array}$ & $\begin{array}{l}\text { Died } \\
N=32(\%)\end{array}$ & $\begin{array}{l}\text { Survived } \\
132(\%)\end{array}$ & $p$-Value \\
\hline \multicolumn{5}{|l|}{ Maternal age } \\
\hline$<20$ years & $23(14.0)$ & $4(17.4)$ & 19 (82.6) & \\
\hline$\geq 20$ years & $141(86.0)$ & $28(20.0)$ & $113(80.0)$ & 0.78 \\
\hline \multicolumn{5}{|l|}{ Maternal education } \\
\hline None & $7(4.3)$ & $2(28.6)$ & $5(71.4)$ & 0.54 \\
\hline Primary & 49 (29.9) & $6(12.2)$ & $43(87.2)$ & \\
\hline Secondary & $81(49.4)$ & $20(24.7)$ & $61(75.3)$ & 0.10 \\
\hline Tertiary & $27(16.5)$ & $4(14.8)$ & $23(85.2)$ & \\
\hline \multicolumn{5}{|c|}{ Maternal income/month } \\
\hline Unemployed/nil & $77(47.0)$ & $14(18.2)$ & $63(81.8)$ & \\
\hline $30-100 \mathrm{~K}$ & $84(51.2)$ & $3(10.0)$ & $27(90.0)$ & \\
\hline$>100 k$ & $3(1.8)$ & $15(26.3)$ & $42(73.7)$ & 0.11 \\
\hline \multicolumn{5}{|l|}{ Maternal parity } \\
\hline Primiparous & $52(31.7)$ & $10(19.2)$ & $42(80.8)$ & \\
\hline $2-4$ & $89(54.3)$ & $17(19.1)$ & $72(80.9)$ & \\
\hline$>4$ & $23(14.0)$ & $5(21.7)$ & $18(78.3)$ & 0.77 \\
\hline \multicolumn{5}{|l|}{ Sex } \\
\hline Male & $71(43.3)$ & $18(25.3)$ & $53(74.7)$ & 0.10 \\
\hline Female & $93(56.7)$ & $14(15.0)$ & $79(85.0)$ & \\
\hline \multicolumn{5}{|l|}{ Discharge weight } \\
\hline$<1000 \mathrm{~g}$ & 37 (22.6) & $13(34.1)$ & $24(64.9)$ & 0.008 \\
\hline 1000-1199 g & $73(44.5)$ & $13(17.8)$ & $60(82.2)$ & \\
\hline$\geq 1200 \mathrm{~g}$ & $54(32.9)$ & $6(11.1)$ & $48(88.9)$ & \\
\hline \multicolumn{5}{|c|}{ Postmenstrual age at discharge } \\
\hline$<35$ weeks & $95(57.9)$ & $25(26.3)$ & $70(73.7)$ & 0.012 \\
\hline$\geq 35$ weeks & $69(42.1)$ & $7(10.1)$ & $62(89.9)$ & \\
\hline \multicolumn{5}{|l|}{ Period in KMC } \\
\hline$<1$ Week & $130(79.3)$ & $20(15.4)$ & $110(84.6)$ & \\
\hline 1-2 weeks & $29(17.7)$ & $9(31.0)$ & $20(69.0)$ & 0.09 \\
\hline$>2$ weeks & $5(3.0)$ & $3(60.0)$ & $2(40.0)$ & 0.04 \\
\hline \multicolumn{5}{|l|}{ KMC support } \\
\hline Supported & $34(79.3)$ & $5(15.6)$ & $29(84.4)$ & \\
\hline Not supported & $130(20.7)$ & $27(20.7)$ & $103(79.3)$ & 0.43 \\
\hline \multicolumn{5}{|l|}{ HIV exposure } \\
\hline Yes & $30(18.3)$ & $7(23.3)$ & $23(76.6)$ & 0.56 \\
\hline No & $134(81.7)$ & $25(18.6)$ & $109(81.3)$ & \\
\hline \multicolumn{5}{|c|}{ Parents living together } \\
\hline Yes & $139(84.8)$ & $24(17.3)$ & $115(82.7)$ & \\
\hline No & $25(15.2)$ & $8(32.0)$ & $17(68.0)$ & 0.09 \\
\hline \multicolumn{5}{|l|}{ SGA } \\
\hline Yes & $98(59.8)$ & $11(11.2)$ & $87(88.8)$ & \\
\hline No & $66(40.2)$ & 21 (31.8) & $45(68.2)$ & 0.001 \\
\hline
\end{tabular}

Table 4 Multivariable analysis on factors independently associated with mortality

\begin{tabular}{lllll}
\hline Variable & OR & Std. Err. & $(95 \% \mathrm{Cl})$ & $P$ \\
\hline Discharge weight $<1000 \mathrm{~g}$ & 3.10 & 1.44 & $1.24-7.74$ & 0.015 \\
Not SGA & 3.54 & 1.90 & $1.23-10.1$ & 0.019 \\
Discharge postmenstrual age $<35$ & 1.13 & 0.68 & $0.34-3.70$ & 0.838
\end{tabular}

education on how to care for preterm babies is given to the mothers; hence, the care is same across education background. Thus it is important that mothers in low resource settings irrespective of social and economic background should be offered special training on how to handle such vulnerable babies in order to improve their chances to survive.

A majority of the infants who died did so in the first month after discharge $22 / 32$ (68.7\%). This finding is similar to that observed in other studies $[14,18,19]$ and this can be explained by the fact that during the first month after discharge the mother is not yet competent in handling the infant, whereas at the same time after the first month the infant has grown and developed more survival mechanisms.

A majority of the infants who died in our study did so from suspected sepsis 16/32 (50.0\%), which was not surprising. Sepsis still contributes significantly to neonatal deaths in the developing countries [4]. Whereas most studies that looked at survival of VLBW babies after discharge did not elaborate of causes of death, some suggested illness in the infants needing to attend hospital prior to death $[13,14,19]$.

We also noted cot death to contribute significantly to deaths after discharge 8/32 (25\%). This may be explained by the fact that majority of our infants were discharged at weight of $<1200 \mathrm{~g}$ and postmenstrual age of $<35$ weeks. Although all our infants were discharged on oral aminophylline, the stability of the medication and whether it was actually given could not be ascertained.

Whereas it is not a common practice in low resource settings to estimate gestational age, it is important that health workers do so, since it should enable them identify babies at risk for apnoea.

\section{Recommendation}

In order to reduce mortality among VLBW infants, they should be discharged preferably at weight $\geq 1200 \mathrm{~g}$ and after measures to prevent sepsis and cot death have been addressed.

\section{Study limitation}

High loss to follow up of $13.7 \%$ and excluded infants of parents not having reliable phone contact might have 
skewed our findings. We could also not ascertain the exact cause of death.

\section{What is already known?}

Preterm/VLBW infants mortality rate is high and it goes beyond the neonatal period.

\section{What this study adds?}

Proportion of VLBW infants that died after discharge from Mulago SCBU, factors attributed to death and possible causes of death among such babies. These may be the same in other low resource settings.

\section{Conclusion}

The mortality observed among VLBW infants discharged from Mulago Special Care Baby Unit of $19.5 \%$ is high. Factors associated with mortality include discharge weight $<1000 \mathrm{~g}$, and post menstrual age at discharge of $<35$ weeks. Most of the deaths were from presumed sepsis and suspected cot death.

\section{Abbreviations}

HIV: Human immunodeficiency virus; KMC: Kangaroo mother care;

SCBU: Special care baby unit; SGA: Small for gestational age; VLBW: Very low birth weight; WHO: World Health Organization

\section{Acknowledgements}

We would like to thank the Mulago Special Care Unit staff and parents who were involved in this study. We would like to thank our research assistant Dr. Kahwa J and our statistician Mr. Opolot F.

\section{Funding}

This study received no external funding.

\section{Availability of data and materials}

The datasets used and/or analyzed during the current study are available from the corresponding author on reasonable request.

\section{Authors' contributions}

Data was entered by YA and NF. Literature search was done by YA and NF, $\mathrm{NJ}$ and $\mathrm{MJ}$ reviewed the methodology and $\mathrm{YV}$ reviewed the write up. All authors read and approved the final manuscript

\section{Competing interest}

The authors declare that they have no competing interest.

\section{Ethics approval and consent to participate}

Ethical approval to conduct this study was obtained from the Uganda National Council of Science and technology. Written informed consent was obtained from the parents.

\section{Consent for publication}

Upon approval to conduct study approval, the Uganda National Council of Science and technology as well as parents of the participants consented to publishing this work

\section{Publisher's Note}

Springer Nature remains neutral with regard to jurisdictional claims in published maps and institutional affiliations.

\section{Author details}

'Department of Paediatrics and Child Health, Makerere University College of Health Sciences, P.O Box 7072, Kampala, Uganda. ${ }^{2}$ Department of Paediatrics and Child Health, Mulago National Referral hospital, Kampala, Uganda.
${ }^{3}$ Department of Pediatrics, Division of Neonatal/Perinatal Medicine, School of Medicine, University of California, San Diego, USA.

Received: 10 June 2018 Accepted: 18 July 2018

Published online: 21 July 2018

References

1. UNICEF. Low birth weight: percentage of infants weighing less than 2500grams at birth. Oct 2014; Available at: http://data.unicef.org/nutrition/ low-birthweight.html. Accessed Oct, 2014

2. UNICEFMHO. United Nations Childrens Fund and World Health Organization. Low birthweight: Country, regional and global estimates. UNICEF. N Y, 2004. 2004

3. Joy LE, Simon C, Jelka Z. 4 million neonatal deaths: When? Where? Why? Lancet. 2005;365(9462):891-900.

4. Lawn JE, Blencowe $H$, Oza S, You D, Lee AC, Waiswa $P$, et al. Every newborn: progress, priorities, and potential beyond survival. Lancet. 2014;384(9938):189-205.

5. Katz J, Lee AC, Kozuki N, Lawn JE, Cousens S, Blencowe H, et al. Mortality risk in preterm and small-for-gestational-age infants in low-income and middle-income countries: a pooled country analysis. Lancet. 2013 Aug 3;382(9890):417-25.

6. Government of Uganda. Save the Children, UNICEF, WHO. Situation analysis of newborn health in Uganda: current status and opportunities to improve care and survival. 2008.

7. Abdallah Y, Namiiro F, Mugalu J, Vaucher Y, McMillan D. Is facility based neonatal care in low resource setting keeping pace? A glance at Uganda's National Referral Hospital. Afri Health sci. 2016;16(2):347-55.

8. Klinger G, Reichman B, Sirota L, Lusky A, Linder N. Collaboration with the Israel neonatal network. Risk factors for delayed discharge home in very-lowbirthweight infants:- a population-based study. Acta Paediatr. 2005;94(11):1674-9.

9. Russell RB, Green NS, Steiner CA, Meikle S, Howse JL, Poschman K, et al. Cost of hospitalization for preterm and low birth weight infants in the United States. Pediatrics. 2007 Jul;120(1):e1-9.

10. Conde-Agudelo A, Belizan JM, Diaz-Rossello J. Kangaroo mother care to reduce morbidity and mortality in low birthweight infants. Cochrane Database Syst Rev 2011 Mar 16;(3):CD002771. doi(3).

11. World Health Organization editor. Kangaroo Mother Care: A practical guide. ; 2003.

12. Mbonye AK, Sentongo M, Mukasa GK, Byaruhanga R, Sentumbwe-Mugisa O, Waiswa P, et al. Newborn survival in Uganda: a decade of change and future implications. Health Policy Plan 2012 Jul;27 Suppl 3:iii104-iii117.

13. Ahmadpour-Kacho M, Pasha YZ, Aliabadi BM. Outcomes of very-lowbirthweight infants after discharge with a discharge weight of 1500 grams. Pediatr Int. 2012 Apr:54(2):196-9.

14. Were FN, Bwibo NO. Neonatal nutrition and later outcomes of very low birth weight infants at Kenyatta National Hospital. Afr Health Sci. 2007 Jun;7(2):108-14.

15. Mokhachane M, Saloojee $H$, Cooper PA. Earlier discharge of very low birthweight infants from an under-resourced African hospital: a randomised trial. Ann Trop Paediatr. 2006 Mar;26(1):43-51.

16. Kugelman A, Reichman B, Chistyakov I, Boyko V, Levitski O, Lerner-Geva L, et al. Postdischarge infant mortality among very low birth weight infants: a population-based study. Pediatrics. 2007 Oct;120(4):e788-94.

17. Ballard JL, Khoury JC, Wedig K, Wang L, Eilers-Walsman BL, Lipp R. New Ballard score, expanded to include extremely premature infants. J Pediatr. 1991 Sep;119(3):417-23.

18. Blencowe $\mathrm{H}$, Kerac M, Molyneux E. Safety, effectiveness and barriers to follow-up using an 'early discharge' kangaroo care policy in a resource poor setting. J Trop Pediatr. 2009;55(4):244-8.

19. Kambarami RA, Chidede O, Pereira N. Long-term outcome of preterm infants discharged home on kangaroo care in a developing country. Ann Trop Paediatr. 2003 Mar:23(1):55-9.

20. Miller MJ, Kiatchoosakun P. Relationship between respiratory control and feeding in the developing infant. Semin Neonatol. 2004;9(3):221-7.

21. Zhao J, Gonzalez F, Mu D. Apnea of prematurity: from cause to treatment Eur J Pediatr. 2011:170(9):1097-105. 